\title{
HUBUNGAN STATUS GIZI DAN GAYA HIDUP DENGAN MENARCHE PADA SISWI KELAS I DAN II SEKOLAH MENENGAH PERTAMA (SMP) NEGERI 2 TAKENGON
}

\author{
The Relationship Of Nutritional Status And Lifestyle With Menarche In Class I And \\ Ii Students Of Middle First (Smp) State 2 Takengon \\ Zulfahmi $^{* 1}$, rauzah tunnur \\ Koresponding email : zulfahmi@uui.ac.id ${ }^{* 1}$ \\ Universitas Ubudiyah Indonesia
}

\begin{abstract}
Abstrak
Setiap remaja akan mengalami pubertas. Pubertas merupakan masa awal pematangan seksual, yakni suat periode dimana seorang anak mengalami perubahan fisik, hormonal, dan seksual serta mampu mengadakan proses reproduksi. Pada awal masa pubertas, kadar hormon LH (Luteinizing Hormone) dan FSH (Follicle-Stimulating Hormone) akan meningkat, sehingga merangsang pembentukan hormon seksual. Pada siswi, peningkatan kadar hormon tersebut menyebabkan pematangan payudara, ovarium, rahim, dan vagina serta dimulainya siklus menstruasi. Di samping itu juga timbulnya ciri-ciri seksual sekunder, misalnya tumbuhnya rambut kemaluan dan rambut ketiak. Penelitian ini bertujuan untuk mengetahui hubungan status gizi dan gaya hidup dengan usia menarche pada siswi kelas I dan II SMP Negeri 2 Takengon. Penelitian ini bersifat deskriptif analitik dengan desain cross sectional dengan populasi seluruh siswi kelas I dan II SMPN 2 Takengon Aceh Tengah yang berjumlah 97 orang. Penelitian ini direncanakan dilaksanakan pada tanggal 20 - 22 Oktober 2016. Data dikumpulkan dengan menggunakan kuesioner selanjutnya dianalisa secara univariat dan bivariat.
\end{abstract}

Kata Kunci: Menarche, status gizi, gaya hidup

\begin{abstract}
Every teenager will experience puberty. Puberty is the initial period of sexual maturation, which is a period in which a child experiences physical, hormonal, and sexual changes and is able to carry out the process of reproduction. At the beginning of puberty, LH (Luteinizing Hormone) and FSH (Follicle-Stimulating Hormone) levels will increase, thereby stimulating the formation of sexual hormones. In female students, increased levels of these hormones cause the maturation of the breasts, ovaries, uterus, and vagina as well as the start of the menstrual cycle. In addition, the emergence of secondary sexual characteristics, such as the growth of pubic hair and armpit hair. This study aims to determine the relationship of nutritional status and lifestyle with the age of menarche in class I and II students of SMP Negeri 2 Takengon. This research is descriptive analytic with cross sectional design with a population of all students of class I and II of Middle Aceh 2 Takengon Middle Aceh, which amounted to 97 people. This research is planned to be carried out on October 20-22, 2016. Data were collected using a questionnaire and then analyzed univariately and bivariately.
\end{abstract}

Keywords: Menarche, nutritional status, lifestyle 
Journal of Healthcare Technology and Medicine Vol. 2 No. 2 Oktober 2016 Universitas Ubudiyah Indonesia

e-ISSN : 2615-109X

\section{Pendahuluan}

Setiap remaja akan mengalami pubertas. Pubertas merupakan masa awal pematangan seksual, yakni suat periode dimana seorang anak mengalami perubahan fisik, hormonal, dan seksual serta mampu mengadakan proses reproduksi. Pada awal masa pubertas, kadar hormon LH (Luteinizing Hormone) dan FSH (Follicle-Stimulating Hormone) akan meningkat, sehingga merangsang pembentukan hormon seksual. Pada siswi, peningkatan kadar hormon tersebut menyebabkan pematangan payudara, ovarium, rahim, dan vagina serta dimulainya siklus menstruasi. Di samping itu juga timbulnya ciriciri seksual sekunder, misalnya tumbuhnya rambut kemaluan dan rambut ketiak (Azwir, 2001).

Gaya hidup juga sangat berkaitan erat dengan perkembangan zaman dan teknologi. Dalam arti lain, gaya hidup dapat memberikan pengaruh positif atau negatif bagi yang menjalankannya. Sebagian besar remaja Indonesia belum dapat memfilter budaya tersebut dengan baik. Pengaruh negatiflah yang timbul dari dalam diri remaja itu sendiri. Namun, sebagian remaja Indonesia kemudian meniru atau mengikuti mode orang barat tanpa memfilternya secara baik dan tepat (Wikipedia, 2011).

Menarche atau menstruasi pertama merupakan salah satu perubahan pubertal yang pasti dialami setiap pada anak perempuan. Usia menarche sangat bervariasi dan lebih berkorelasi dengan maturasi tulang di banding umur kronologik. Anak perempuan mempunyai tanda pubertas pada umur 12 tahun dan umur rata-rata 12,5 tahun (Nike, 2009).

Faktor yang mempengaruhi usia menarche antara lain adalah faktor Internal yang meliputi organ reproduksi, hormonal, dan penyakit sementara faktor eksternal meliputi status gizi, pengetahuan orang tua, dan gaya hidup. Menurut Soekirman (2006) setiap orang dalam siklus hidupnya selalu membutuhkan dan mengkonsumsi berbagai bahan makanan yang mengandung zat gizi. Zat gizi mempunyai nilai yang sangat penting yaitu untuk memelihara proses tubuh dalam pertumbuhan dan perkembangan, terutama bagi mereka yang masih dalam pertumbuhan.

SMP Negeri 2 Takengon merupakan salah satu sekolah menengah lanjutan pertama yang ada di Kabupaten Aceh Tengah. Berdasarkan hasil survey awal yang penulis lakukan diketahui bahwa rata-rata usia menarche siswi SMP Negeri 2 Takengon adalah 12,5 tahun. Siswi SMP Negeri 2 Takengon sering menghabiskan waktu diluar rumah bersama temanteman dan kurang melakukan aktivitas olah raga, dan berdasarkan survey awal yang juga penulis lakukan siswi SMP Negeri 2 Takengon memiliki berat badan dan tinggi badan yg normal. 


\section{Metode Penelitian}

Penelitian ini bersifat deskriptif analitik dengan pendekatan cross sectional yaitu pendekatan penelitian dimana pengumpulan data untuk variabel independen dan variabel dependen dikumpulkan dalam satu waktu yang bersamaan atau dalam satu periode tertentu (Notoatmodjo, 2002).

Populasi dalam penelitian ini adalah seluruh siswi kelas I dan II SMPN 2 Takengon Aceh Tengah yang berjumlah 97 orang. Sampel dalam penelitian ini adalah total populasi yaitu sebanyak 97 orang.

Data Primer, data yang dikumpulkan langsung dari responden meliputi data status gizi, gaya hidup dan data tentang usia menarche. Untuk melengkapi data primer peneliti memperoleh data dari SMP Negeri 2 Takengon Aceh Tengah. Setelah mendapat izin dari kepala sekolah, peneliti akan memperkenalkan diri dan menjelaskan terlebih dahulu kepada responden tentang maksud dan tujuan penelitian dengan mengajukan surat permohonan menjadi responden. Responden yang terpilih dan bersedia menjadi responden akan diminta menandatangan surat pernyataan persetujuan menjadi responden, selanjutnya peneliti akan membagikan kuesioner kepada responden dibantu oleh seorang numerator.

a. Umur

\section{Tabel 1}

Distribusi Responden Berdasarkan Umur di SMP Negeri 2 Takengon Tahun 2016

\begin{tabular}{|c|c|c|c|}
\hline No & Umur & f & \% \\
\hline 1 & $11-13$ tahun & 91 & 93,8 \\
2 & $14-16$ tahun & 6 & 6,2 \\
\hline & Total & 97 & 100 \\
\hline
\end{tabular}

Tabel 1 menunjukkan bahwa dari 97 responden berdasarkan umur berada kelompok umur 12-13 tahun yaitu sebanyak 91 orang $(93,8 \%)$. 
Journal of Healthcare Technology and Medicine Vol. 2 No. 2 Oktober 2016

Universitas Ubudiyah Indonesia

e-ISSN : 2615-109X

Tabel 2

b. Distribusi Responden Berdasarkan Manarche di SMP Negeri 2 Takengon Tahun 2016

\begin{tabular}{|c|cc|c|c|}
\hline No & Manarche & f & \% \\
\hline 1 & Sudah & 57 & 58,8 \\
2 & Belum & 40 & 41,2 \\
\hline & \multicolumn{2}{|c|}{ Total } & 97 & 100 \\
\hline
\end{tabular}

Tabel 2 menunjukkan bahwa dari 97 responden berdasarkan menarche berada pada kategori sudah yaitu sebanyak 57 orang $(58,8 \%)$

\section{c. Status Gizi}

Tabel 3

Distribusi Responden Berdasarkan Status Gizi di SMP Negeri 2 Takengon Tahun 2016.

\begin{tabular}{|c|l|c|c|}
\hline No & \multicolumn{1}{|c|}{ Status Gizi } & f & \% \\
\hline 1 & Normal & 84 & 86,6 \\
2 & Tidak normal & 13 & 13,4 \\
\hline & Total & 97 & 100 \\
\hline
\end{tabular}

Dari hasil penelitian menunjukkan bahwa dari 13 responden yang mempunyai status gizi tidak normal terdapat 10 orang $(76,9 \%)$ yang belum menarche dan dari 84 responden yang mempunyai status gizi normal terdapat 54 orang $(64,3 \%)$ yang sudah menarche. Hasil analisis data menunjukkan bahwa ada hubungan antara status gizi dengan menarche di SMP Negeri 2 Takengon dengan nilai $\mathrm{p}$ value 0,012 .

Menurut Almatsier (2005), status gizi adalah keadaan tubuh sebagai akibat konsumsi makanan dan penggunaan zat-zat gizi. Dibedakan antara status gizi buruk, kurang, baik dan lebih. Konsumsi gizi makanan pada seseorang dapat menentukan tercapainya tingkat kesehatan, atau sering disebut status gizi. Apabila tubuh berada dalam tingkat kesehatan gizi optimum, di mana jaringan jenuh oleh semua zat gizi, maka disebut status gizi optimum. Dalam kondisi demikian tubuh terbebas dari penyakit dan mempunyai daya tahan yang setinggi-tingginya. Apabila konsumsi gizi makanan pada seseorang tidak seimbang dengan kebutuhan tubuh maka akan terjadi kesalahan akibat gizi (malnutrition). Malnutrition ini 
Journal of Healthcare Technology and Medicine Vol. 2 No. 2 Oktober 2016

Universitas Ubudiyah Indonesia

e-ISSN : 2615-109X

mencakup kelebihan nutrisi/gizi disebut gizi lebih (overnutrition), dan kekurangan gizi atau gizi kurang (undernutrition) (Notoatmodjo, 2007).

Munurut asumsi peneliti ada hubungan dengan status gizi dengan minarche hal ini dikarenakan siswi di SMP Negeri 2 Takengon banyak yang status gizi normal, karena mereka sering mengkonsumsi makan yang bergizi dan berprotein, namun ada juga yang status gizi tidak normal karena mereka kurang mengkonsumsi makan yang bergizi banyak mengkonsumsi makanan yang berlemak.

\section{Hubungan Gaya Hidup Dengan Menarche}

Dari hasil penelitian menunjukkan bahwa dari 32 responden yang mempunyai gaya hidup yang kurang baik terdapat 22 orang $(78,1 \%)$ yang belum menarche, dan dari 65 responden yang mempunyai gaya hidup yang baik terdapat 35 orang $(53,8 \%)$ yang sudah menarche. Hasil analisis data menunjukkan bahwa tidak ada hubungan antara gaya hidup dengan menarche di SMP Negeri 2 Takengon dengan nilai $p$ value 0,237. Menurut G.Stanley Heal (2000) remaja adalah peringkat di mana seseorang itu mengalami konflik dan tekanan. Remaja sering kecewa dan emosi mereka tidak stabil. Hal ini kerana remaja mengalami faktor biologi dan psikologi yang berubah. Remaja akan mengalami beberapa tugas perkembangan yang melibatkan kebolehan, pengetahuan, fungsi dan sikap yang mempengaruhi remaja tersebut.

Remaja sama ada lelaki ataupun perempuan semuanya merupakan aset negara. Mereka sama penting sebagai sumber tenaga manusia yang akan merencana dan menggerakkan pembangunan Negara. Bedanya hanyalah dari segi keperluan dan fisik masing-masing. Remaja hari ini bakal mewarnai pentas pembangunan Negara dan penentu kepada jatuh bangunnya generasi akan datang. Remaja hari ini adalah insan-insan yang bertanggungjawab untuk mengisi keperluan Negara di masa hadapan. Walau bagaimanapun, remaja pada masa kini sedang tenggelam dalam arus keruntuhan akhlak dan moral lantaran tidak memiliki daya tahan spiritual yang kuat (Wikipedia, 2011). 
Journal of Healthcare Technology and Medicine Vol. 2 No. 2 Oktober 2016

Universitas Ubudiyah Indonesia

e-ISSN : 2615-109X

Menurut asumsi peneliti tidak ada hubungan gaya hidup dengan minarche hal ini dikarenakan banyak gaya hidup siswa yang baik. Gaya hidup yang baik dikarenakan mereka tidak mengikuti gaya hidup orang asing, namun ada juga yang gaya hidup yang kurang baik terhadap menarche karena mereka mengiku gaya hidup orang asing, maka gaya hidup mereka kurang baik.

\section{Kesimpulan}

Berdasarkan penelitian yang dilakukan tentang hubungan status gizi dan gaya hidup dengan menarche pada siswi kelas 1 SMP Negeri 2 Takengon, maka dapat disimpulkan bahwa:

1. Ada hubungan antara status gizi dengan menarche di SMP Negeri 2

Takengon dengan nilai $\mathrm{p}$ value 0,012 .

2. Tidak ada hubungan antara gaya hidup dengan menarche di SMP Negeri 2 Takengon dengan nilai $\mathrm{p}$ value 0,237 .

\section{Daftar Pustaka}

Aliance, 2001. Pemantauan Status Gizi, Bina Rupa Aksara, Jakarta Almatsier, P, 2002. Ilmu Gizi Dasar, Rhineka Cipta, Jakarta Almatsier, 2005. Prinsip

Dasar Ilmu Gizi, Gramedia Pustaka, Jakarta Arikunto, . 2003. Prosedur Penelitian, Rhineka Cipta, Jakarta Arsyandi, 2007, Pemantau Pelayanan Kesehtan, Depkes RI, Jakarta

Asniar, 2001, Faktor Penghambat Menstruasi Pada Remaja, CV Aneka Cipta, Jakarta

Azwir, 2001, Pengetahuan Remaja Tentang Menstruasi, Gramedia Utama, Jakarta

Depkes RI, 2005. Buku Saku Bidan, Depkes, Jakarta Fidiani, 2007. Ilmu Gizi

Dasar. Bina Rupa Aksara, Jakarta Notoatmodjo, 2002. Metodelogi

Penelitian, Rhineka Cipta, Jakarta Notoatmodjo, 2007.Ilmu Kesehatan Masyarakat, Rhineka Cipta, Jakarta,

Nike, 2008. Usia Menarche dan factor-faktor yang mempengaruhinya. Dalam http:// www.psikologi. Go.id

Nugroho, 2007. Determinasi Gizi Buruk, Sagung Seto, Jakarta Nurie, 2004.

Menstruasi Yang Pertama, Fitramaya, Jakarta Mardiana, 2002. Usia

Menarche, Gramedia Psutaka Utama, Jakarta Michle, 2001, Remaja

Dan Pemasalahan, Jakarta

Pakpahan, 2009. Kesehatan Reproduksi. Fitramaya, Jakarta Paath,

dkk.2005. Menarche. Sagung Seto, Jakarta

Prawirohadjo, 2005. Ilmu Kandungan, Yayasan Bina Pustaka Sarwono, Jakarta

Rulliana. 2003, Kehamilan Dan Tanda Bahaya, Tarsito, Bandung. 
Journal of Healthcare Technology and Medicine Vol. 2 No. 2 Oktober 2016

Universitas Ubudiyah Indonesia

e-ISSN : 2615-109X 